\title{
On Not Forcing the Question: Criticism and Playing Along
}

\section{1}

Critics are contemptible. How else can we explain the stream of taunts and mockeries directed at them? Critics are, first of all, wannabes: they wish they were artists, but they aren't. This leads to a pervasive envy, captured well in Susan Sontag's summary judgment: "Interpretation is the revenge of the intellectual upon the artist" (Sontag 1990 [1966], 7). Critics wish to share in the glory of the artist, but they don't: "I have been all over the world and I have never seen a statue of a critic." (This gibe is variously attributed to Jean Sibelius or Leonard Bernstein.) The more exorbitant the artistic ambition, it seems, the greater the contempt for those who merely interpret. Gustave Flaubert, a man with ambitions, implies that the creative defect in critics is analogous to the moral defect of spies: people "write criticism because they are unable to be artists, just as a man unfit to bear arms becomes a police spy" (Flaubert 1979, xv). Elsewhere, Flaubert makes his moral point differently: "Criticism occupies the lowest place in the literary hierarchy; as regards form, almost always; and as regards 'moral value,' incontestably. It comes after rhyming games and acrostics, which at least require a certain inventiveness.” (xv)

Incompetent, resentful, underhand, policing - such is the standard litany of the critic's faults. In these attacks, the critic is always in a derivative relation to the artist and the artwork; he is a parasite, a kind of tick. This attitude toward critics is neither new nor rare; I certainly could have chosen other examples. What I want to emphasize is the intensity of feeling that animates this current of thought, and the grandiosity of its terms. A statue for the artist! Greatness lies with the artist, paltriness with the spying critic. The whole relationship seems colored by very basic, even primitive, experiences and fantasies, as if "His Majesty, the Baby (Artist)" felt constantly hemmed in, controlled, misunderstood, or disciplined by some witnessing or surveilling presence - the critic as a never "good-enough" minder.

In any case, that is the direction I want to travel in this essay. I wish to consider the problem of 'poetic critique' as encompassed in this scenario of a creative actor and a witnessing other. The twinning of creator and witness is, in one sense, existential: every human act, creative or otherwise, is born into a world in which others have come before. The witnessing other may enable this creative act, like oxygen helping the spark to flame, or might disable it, a wet blanket thrown over that spark too soon. But as is signaled by my riffing above on psychoanalytic mottos - "His Majesty, the Baby" (Freud) and "good enough mother" (Winnicott) - I also take psychoanalysis to be a privileged discourse for any inquiry into the question of poetic critique. That is 
because the work of analysis is always a joint production of patient and analyst. What is brought forth through the complex weave of unconscious materials, transference effects, and interpretation is new meaning that is also always old: it is both poiesis and critique. The psychoanalytic situation suggests that while the creative and the interpretive are necessarily co-present dimensions, they are not co-incident just two names for the same thing - nor, for that matter, are they fully separable. I will argue, in fact, that the question of the relation of the creative and the critical, of that which brings newness into the world - poiesis - and that which works on what is found in the world, may benefit from not being broached at all.

My warrant for such an approach is the work of psychoanalyst D.W. Winnicott. Here is perhaps the best-known statement of his influential ideas about the transitional object, about illusion and play, and the witnessing presence necessary to such play:

The transitional object and the transitional phenomena start each human being off with what will always be important for them, i.e. a neutral area of experience which will not be challenged. Of the transitional object it can be said that it is a matter of agreement between us and the baby that we will never ask the question: 'Did you conceive of this or was it presented to you from without?' The important point is that no decision on this point is expected. The question is not to be formulated. (Winnicott 1991 [1971], 12)

Winnicott remains focused on this "neutral" or "intermediate" $(11,13,105)$ area of experience for his entire career. It is, he believes, the very ground of creative "experiencing" $(2,6,14)$ in all of life (he often uses this odd gerund to keep our eye on process rather than product). If this passage through the "experiencing" of a zone of "illusion" $(3,11)$ - the word illusion, we should point out, derives from in-ludere, in play; - if this zone is not happily traversed, it is likely the child will have troubles in life, will find it hard to consider life meaningful. These transitional phenomena in which the relation between subjective and objective is not broached are, Winnicott believes, essential for human being in its totality:

It is assumed here that the task of reality-acceptance is never completed, that no human being is free from the strain of relating inner and outer reality, and that relief from this strain is provided by an intermediate area of experience which is not challenged (arts, religion, etc.). This intermediate area is in direct continuity with the play area of the small child who is 'lost' in play. (13)

The swiftness and the unobtrusiveness with which Winnicott jumps from the minutiae of child analysis to the furthest reaches of "culture" can make it hard to grasp the claim he is making. The child "lost" in play, the child with whom the interpreting other has a tacit agreement not to force certain questions, is in "direct continuity" with any grown person participating in the aesthetic and religious dimensions of life. What we learn from child psychoanalysis, in other words, may be fruitfully transposed to analyses of the arts. This is hardly a new idea. Psychoanalysis has never shied away from extending its interpretive domain beyond the consulting room; 
Freud himself was very interested in using the tools of psychoanalysis to interpret artists, artworks, and aesthetic experience more generally. But there is something in Winnicott's work - in his style of presentation as much as in the content of his ideas - that is unique in the psychoanalytic canon, and that suggests other lessons than Freud's might be available.

Adam Phillips argues that the "genre of simplicity in which Winnicott writes, a wry version of pastoral, is in fact a kind of elusiveness. But the shrewd ingenuousness of his writing, unprecedented in the psychoanalytic tradition, is consistent with one of his therapeutic aims: to protect the privacy of the self in the making of personal sense and, by the same token, personal non-sense” (Phillips 1988, 14). This seems right, and also complicated: on the one hand, the explanatory reach claimed by Winnicott's idea of this unforced "neutral zone" - "arts, religion, etc." [emphasis mine] is exorbitant, and Winnicott might thereby be said to display some of the grandiosity I was flagging above. On the other hand, this grandiosity is displayed in such a recessive and "elusive" manner that it is hard to know if one has understood it correctly. Some of this is due to Winnicott's strong predilection for the passive voice: "Of the transitional object it can be said"; "The important point is that no decision on this point is expected"; "The question is not to be formulated." Passivity is so charged for Winnicott that, as Barbara Johnson has remarked, objects themselves are invested with agency so that their own pathos can be registered: the transitional object's "fate is to be gradually allowed to be decathected [...] It is not forgotten and it is not mourned. It loses meaning" (Johnson 2008, 100). When Phillips writes that Winnicott's style "is consistent" with his "therapeutic aim" to "protect the privacy of the self," it is both the patient's self and his own that Winnicott has in mind: "The need of the self to be both intelligible and hidden that he found in his patients is reflected in his style." (Phillips 1988, 14)

At the same time, Winnicott's elusiveness, his desire to remain hidden, is curiously vulnerable and exposed. ${ }^{1}$ It is this simultaneously recessive and vulnerable posture toward the work of psychoanalytic interpretation that sets Winnicott apart. In one paper, he invokes the proverbial armchair philosopher only to suggest that if the philosopher gets out of his chair and on the floor with the playing child things would look different. Winnicott's elusiveness is deployed from a position on the floor, as it were. Compare this to Freud in his famous analysis of the child's game of fort-da in Beyond the Pleasure Principle. Doing everything he can to keep a distance from the context of his observation, Freud refers to his grandson drily as a "little boy of one and a half" (Freud 1961 [1920], 8); and perhaps to keep at bay any worries that his family relationship to the child has led him to impute cleverness where there is none, Freud makes clear that the "child was not at all precocious in his intellectual development" (8). How, finally, does Freud come to understand that the "loud, longdrawn-out o-o-o-o" is in fact the word "fort"? He does not tell us; he merely reports

1 On the importance of "self-exposure” in criticism, see Chaouli 2013. 
that the child's "mother and the writer of the present account were agreed in thinking” (9) that it was so. Reading this passage with Winnicott in mind, we might remark that here, too, we have a kind of exhibition of hiddenness. But there is a crucial difference: in Freud's case the several layers of recessiveness - an obscured family relation, avoidance of the I, passive voice - are in service to analytic power rather than the kind of "vulnerability" we find in Winnicott. "One day I made an observation that confirmed my view" (9), Freud writes, and goes on to describe the famous play with the spool. "The interpretation of the game then became obvious" (9). Case closed.

Child analysis was never a central concern of Freud's, even as his forays into this practice (think of "Little Hans") foreshadowed important developments in the psychoanalytic tradition. Winnicott was a pediatrician before he was an analyst, but even if he had not been, he might well have steered toward the interpretation of children, since the two dominant schools of psychoanalysis in Britain, those of Anna Freud and Melanie Klein, relied so fundamentally on child analysis. Winnicott was a major figure in what has come to be called the "Third Way," along with Marion Milner, Masud Khan, and others. In "Playing: A Theoretical Statement," Winnicott signals his divergence from Klein, in particular: "in so far as she was concerned with play," it was "almost entirely with the use of play" (Winnicott 1991 [1971], 39). She moves too efficiently, Winnicott suggests, from observation to interpretation, as Freud for example moves from the fort-da game to the "obvious" interpretation that this game meant "mastery." The "psychoanalyst has been too busy using play content to look at the playing child," Winnicott writes, "and to write about playing as a thing in itself. It is obvious that I am making a significant distinction between the meanings of the noun 'play' and the verbal noun 'playing."' (40)

What, exactly, is Winnicott's disagreement with Klein? What's the difference between "play” and “playing”? Klein's clinical acumen was much celebrated, and her innovations in the technique of child analysis were widely influential. It is also true that Klein took an extremely active interpretive posture, something that, from her earliest papers, she argued was necessary:

\footnotetext{
As soon as the small patient has given some sort of insight into his complexes - whether through his games or his drawings or phantasies - I consider that interpretation can and should begin. This does not run counter to the well-tried rule that the analyst should wait till the transference is there before he begins interpreting, because with children the transference takes place immediately. (Klein 1949 [1932], 47)
}

With small children, Klein explains, separation between conscious and unconscious behavior is only tenuously in place, with the result that many defenses (such as those inhibiting transference) are not present. At the same time, anxiety is much more disabling in many children than in many older patients. This anxiety also calls for early intervention. A girl of three that Klein calls Trude "exhibited [...] much anxiety at her very first coming." Klein tells us that "in such patients prompt interpretation was the 
only means of lessening anxiety” (53). Children present special problems calling for swift and vigorous interpretive intervention.

Reading Klein can be a harrowing experience, not only because the clinical material from small children is so often violent and florid, but also because her own interpretive vigilance is so unrelenting. Klein's last publication was a detailed case study of a ten-year-old boy, Richard, whom she treated during the war. Here is a taste of what it is like:

Richard [...] often feared that a nasty man - a kind of tramp - would come and kidnap Mummy during the night, [...].

Mrs $K$. asked how he thought the tramp would get into Mummy's room.

Richard said (after some resistance) that he might get in through the window: perhaps he would break in.

Mrs $K$. asked if he also wondered whether the tramp would hurt Mummy.

Richard (reluctantly) answered that he thought the man might hurt her, but he, Richard, would go to her rescue.

Mrs K. suggested that the tramp who would hurt Mummy at night seemed to him very much like Hitler who frightened Cook in the air-raid and ill-treated the Austrians. Richard knew that Mrs K. was Austrian, and so she too would be ill-treated. At night he might have been afraid that when his parents went to bed something could happen between them with their genitals that would injure Mummy.

Richard looked surprised and frightened. (Klein 1961, 20-21)

This exchange comes from the first session. The analysis continues in this vein for another four hundred pages.

At ten years of age, Richard is more verbally fluent than many of Klein's younger patients. But play with toys is as swiftly reduced to its unconscious meaning as Richard's verbal material: “[I]n the first hour," Klein writes of Peter, not quite four years old, "his knocking together of the two carriages and horses had been followed by his remarking that he had got a new little brother. So I continued my interpretation and said: 'You thought to yourself that Daddy and Mummy bumped their thingummies together and that made your brother Fritz be born"” (Klein 1949, 42). Whatever the efficacy of Klein's clinical work - and there seems to be lots of evidence that she helped her young patients very much - her interpretive method cannot help seeming aggressive. There is, in the end, a known code to which fantasies can, and must, be reduced: the code of oedipal feelings, primal scenes, the entire Freudian armory that is unquestioningly invoked even as it is constantly being revised and reshaped by Klein's clinical experience. Toys bumping = thingummies bumping. "In so far as she was concerned with play," Winnicott had remarked about Klein, it was "almost entirely with the use of play" (Winnicott 1991 [1971], 39). The child's use of play, and hers. The idea that play, as an act of creativity, would express the "need of the self to 
be both intelligible and hidden [emphasis mine]" (Phillips 1988, 14), is not a concern of Klein's.

I noted earlier Winnicott's strange preference for “experiencing” where we might expect "experience," and his choice of "playing" over play comes from the same disposition: namely, to avoid relapsing, for as long as feasible, into interpretive abstraction - "play" (abstraction) serves or means "mastery" (abstraction); or, toys bumping means thingummies bumping. But interpretive abstraction can also lead to over-estimation of the objective dimension itself, of the toy, game, or creation, understood as separate from, even if revealing, the secrets of the child. This version of interpretive abstraction loses sight of the mystery of creativity itself: "When psycho-analysis has attempted to tackle the subject of creativity it has to a large extent lost sight of the main theme," Winnicott writes in "Creativity and Its Origins." "It is possible to take Leonardo Da Vinci and make very important and interesting comments on the relationship between his work and certain events that took place in his infancy" (Winnicott 1991 [1971], 69). But:

It is inevitable that such studies of great men tend to irritate artists and creative people in general. It could be that these studies [...] are irritating because they look as if they are getting somewhere, as if they will soon be able to explain why this man was great and that woman achieved much, but the direction of inquiry is wrong. The main theme is being circumvented, that of the creative impulse itself. The creation stands between the observer and the artist's creativity. (69)

Let me pause here and gather up some threads. I began with the tradition of spleen directed at the critic. Winnicott understands such rage, though he calls it, more mildly, "irritation," and suggests it might be due to interpretation (or what I am also calling criticism) "looking like it is getting somewhere." Interpreters might "get somewhere" by recourse to a code, but also - and this is more strange - by letting "the creation [stand] between the observer and the artist's creativity." Critical methods that over-invest the object in this latter way are in fact over-investing their method, they are eager to "get somewhere," to basically take over control of the playing. But what would it mean to stay focused on the artist's creativity, not ignoring the creations but understanding them as emblems of a process that should be allowed to be ongoing, not swiftly resolved into meaning? This is where Winnicott's insistence on "not forcing the question" becomes his central technical contribution. To force the question - to require an answer to the question of whether this object is made up or found - is, finally, to over-value the object. It is to ossify it to the extent that it becomes an object in the interpreter's own itinerary, like a baton being passed. But if the child or artist has passed the baton, he or she is no longer playing. In worrying about the ontological status of the object, play is suspended, or ruined. 


\section{2}

I want now to pull the focus out from child analysis to ask some questions about interpretation and aesthetic experience more broadly construed. What Winnicott is so intent upon - not forcing the question, leaving the intermediate space unchallenged, its paradoxes unresolved - can sometimes look familiar, and sometimes strange. Granting for the moment the possibility of "direct" continuity between infantile play and "arts, religion, etc.," we could argue that the tacit compact between creative behavior and its witness (who might now, in our wider focus, be a reader, or theatergoer) not to ask certain questions goes by some familiar names: the "suspension of disbelief," for example. Here is Bill Watterson, the creator of the Calvin and Hobbes comic strip, on this topic:

The so-called 'gimmick' of my strip - the two versions of Hobbes - is sometimes misunderstood. I don't think Hobbes as a doll miraculously comes to life when Calvin's around. Neither do I think of Hobbes as the product of Calvin's imagination. The nature of Hobbes's reality doesn't interest me, and each story goes out of its way to avoid resolving the issue. (qtd. in Groensteen 2013 [2011], 129)

This is satisfyingly Winnicottian in its staging: a choice is there - animated stuffed tiger, or imaginary projection? - and that choice is refused. "The nature of Hobbes' reality doesn't interest" Watterson, and if we are reading the strip in a Winnicottian spirit, it won't interest us either. We'd be nincompoops if we worried too much about Hobbes' reality, just as we would be if we worried the problem of Hamlet's reality when we go to the theater. If Watterson was playing with a real child named Calvin, then this readiness not to ask a question would be in service of continued play. Calvin is not real of course, but Watterson's treatment of the Calvin/Hobbes relationship works as if he is, and in any case is in service of keeping the play proceeding, and the strip open-ended: "each story goes out of its way to avoid resolving the issue."

This interest in keeping play proceeding, what Winnicott calls an interest in "playing" rather than merely "play," is one result of not forcing the question. One way in which creator and interpreting witness come together to produce something that we might call "poetic critique," is by understanding the playing involved as part of a process that both precedes and succeeds the objects created and interpreted. There are some kinds of "playing along" that have, strictly speaking, no beginning or ending, merely a series of resting-places and way-stations. Socratic dialogue, a special kind of "play," often has this feeling; and perhaps philosophy, concerned as it is with fundamental problems that hide their origins and ends, has a special closeness to our problem of playing along. (If so, it is not without paradox: not forcing the question by forcing a multitude of questions!) In the intricate final movement of Stanley Cavell's The Claim of Reason, there are a few curious pages on dolls. Cavell has been asking questions about identity, about bodies, about our idea that bodies 
are living, and so on. He has just finished ruminating on the relationship between a statue and the stone of which it is made. Suddenly, a new theme is introduced:

A statue has aspects. By walking around it, by the changing light, in your changing mood, the figure can be seen as vulnerable, as indomitable, as in repose, as if in readiness. A doll has occasions. I am thinking of a rag doll. It can be happy or sad, fed or punished. In repose it has aspects, for example it can be seen as sleeping or dead or sun-bathing. But only if you do not know which is true. (Cavell 1979, 401)

The distinction between "aspects" and "occasions" Cavell develops here points to two different kinds of life we are prepared to impute to non-living things. Aspects are, as it were, snapshots of the "life" of the statue, always traceable to our changing visions: "the figure can be seen [emphasis mine] as vulnerable," etc. "Occasions," by contrast, imply an ongoingness, an insertion of the figure in a history that determines the "truth" that only your not knowing would allow you to see the doll as merely a matter of aspects - as "sleeping or dead or sun-bathing." But where does this "truth" beyond aspects come from?

The simple answer is this: "There is only one who knows which is true, the one whose doll it is" (401). We're back at the relation between the one who knows - the child - and the one who wishes to know, the observer, the player-along, here the philosopher. (Of course, in the psychoanalytic version, the child both knows and does not know.) Cavell describes a series of exchanges about the doll between its "owner" - he questions that word too - and the observer. The point of these exchanges is that even if the observer defers - "At some point my say comes to an end. I defer to the one whose doll it is" (402) - the "truth" of the doll's "occasion" is nevertheless a joint production.

There are criteria in terms of which I settle judgments about the (other's) doll. To know whether a concept applies I have to look - at the doll. I have to determine if I can see it in this way, get that occasion for it to dawn for me. Otherwise I am only humoring the one whose doll it is. Perhaps I am tired, or have a head-ache. I cannot in any case experience the meaning of the words about the doll. The doll seems rags. I still know what a doll is; but at the moment I am dollblind. (401-402)

The fact that you can know what a doll is and be doll-blind says something about the kind of knowledge we are dealing with. This knowledge of what a doll is does not help us see the doll, does not help us overcome doll-blindness, when it hits. Knowing what a doll is does not help us "enter into its history, achieve the spirit in which concepts of life are applied to it” (403). To “enter into its history,” if I understand correctly, is neither to deny the doll - to say it is just rags - nor merely to defer to the one whose doll it is; it is to "get that occasion to dawn for me." Notice here that Cavell is describing a situation in which too restricted a focus on the object - on "what a doll is" - will fail in understanding the reliance of that object on a process, an "occasion," that exceeds it. Getting an "occasion to dawn for me" is a kind of imaginative 
investment that is neither "poetic" nor "critical," or rather is both, but neither at the expense of the other.

Such imaginative investment extends the "history" of the doll in the way we might hope sensitive criticism allows its "occasions" to continue their histories. It does not, in any case, make too much of the form, or "reality," of the doll, knowing that its life does not exist there. It does not hijack its history either. Toward the end of these penetrating pages on the "occasions" of the doll's life, Cavell forwards his own unforced question: "What is the doll? (I would like to answer that question because I feel I know everything there is to know about dolls. But I would like not to have to answer it since of course I know absolutely nothing about dolls that others do not know)" (404). Some questions, the answers to which everyone knows but no one knows differently, are better left unanswered. Cavell's method - at once poetic and critical - tacks between the urgency of answering and the urgency of not answering; his genius is in his ability to ask questions for which such tacking is the best response. It is not incidental that child's play - with an other, since there always is an other, one hopefully fending off "doll-blindness" - provides such a powerful occasion to turn away from the too-quick answer in favor of open sailing on a sea of questions. It is child's play, in any case, that here provides Cavell with an "occasion" to exercise and exemplify his unique method of poetic critique, a method for which, as his book's epigraph from Ralph Waldo Emerson has it, "it is not instruction, but provocation, that I can receive from another soul” (iii).

\section{3}

The English literary critic William Empson was well acquainted with the contempt in which critics were held: “Critics, as 'barking dogs,' [...] are of two sorts: those who merely relieve themselves against the flower of beauty, and those, less continent, who afterwards scratch it up" (Empson 1947, 9). But he remains unfazed:

I myself, I must confess, aspire to the second of these classes; unexplained beauty arouses an irritation in me, a sense that this would be a good place to scratch; the reasons that make a line of verse to give pleasure, I believe, are like the reasons for anything else; one can reason about them; and while it may be true that the roots of beauty ought not to be violated, it seems to me very arrogant of the appreciative critic to think that he could do this, if he chose, by a little scratching. (9)

At first blush, the "appreciative" critic, who eschews scratching like a barking dog, might seem more Winnicottian in his interpretive restraint than Empson. But it has never been a question of not asking questions at all; Winnicott's concern is with the kind of digging that looks too much "like it is getting somewhere," as if it really were possible to get fully at the root of things (about which Empson is skeptical). Like Cavell, Empson practices poetic critique as a kind of interpretive errancy, getting all kinds of places but perhaps nowhere in particular. 
Empson's first book was Seven Types of Ambiguity, a work about which one could well ask why it begins where it does or ends where it does. In the Preface to the second 1947 edition of his book, Empson considers some of the criticisms he received after the publication of the first edition. The prevailing mood of the critics seems to have been exasperation. And it is an understandable response: Empson's 'method,' if it is one, is to unspool a variety of meanings from a piece of verse like a peddler unpacking his wares for visual effect; to consider how these shades of meaning might unite to produce the power of the poetry; to briefly admire the array again; and then move on to another example. In reply, Empson focuses his response on one review by James Smith, who had argued that Empson fails miserably in what is the "first business" of the critic, namely "the passing of a judgment on value" (xii). Empson admits that Smith is correct in this charge: "Even in the fuller examples, where I hope I have made clear what I feel about the poem as a whole, I don't try to 'make out a case' for my opinion of its value" (xiii). This is because Empson understands the role of judgment to be not some one-off conclusion or ruling, but rather a structural assumption of the work of interpretation itself: "The judgment indeed comes either earlier or later than the process which I was trying to examine. You think the poem is worth the trouble before you choose to go into it carefully, and you know more about what it is worth when you have done so" (xiii). The judgment of value is implied in the work of interpretation itself, in other words; it both precedes it as the notion that interpretation is worth undertaking right here, with this poem, and extends beyond any delimited act of practical criticism: you then know more about "what it is worth," but not perhaps everything.

The question of value judgments gets entangled, through Empson's generous quotation of Smith's negative review, with a version of the Winnicottian question that must not be forced. Winnicott had written that "it is a matter of agreement between us and the baby that we will never ask the question: 'Did you conceive of this or was it presented to you from without?"' (Winnicott 1991 [1971], 12) In the present context, we might paraphrase this as follows: "Is this poem a thing in the mind or a thing in the world?" Mr. James Smith has decided in advance how he answers this question, as it regards the ambiguities analyzed by Empson:

\footnotetext{
Is the ambiguity referred to that of life - is it a bundle of diverse forces, bound together only by their co-existence? Or is it that of a literary device - of the allusion, conceit, or pun, in one of their more or less conscious forms? If the first, then Mr. Empson's thesis is wholly mistaken; for a poem is not a mere fragment of life; it is a fragment that has been detached, considered, and judged by a mind. A poem is a noumenon rather than a phenomenon. If the second, then at least we can say that Mr. Empson's thesis is exaggerated. (qtd. in Empson 1947, xii)
}

"A poem is a noumenon rather than a phenomenon," a thing in the mind, detached from the world by the mind, which also makes a judgment about it. This is Smith's position. Empson is less sure. He brings up the widely shared position that an artist's judgment about his or her own work "may be wrong” (Empson 1947, xiv). 
As I remember, one of the best-known short poems by Blake is actually crossed out in the notebook which is the only source of it. This has no bearing on any 'conflict' theory; it is only part of the difficulty as to knowing whether a poem is a noumenon or a phenomenon. Critics have long been allowed to say that a poem may be something inspired which meant more than the poet knew. (xiv)

The "difficulty" here is that the poem is both a noumenon and a phenomenon, or neither only one or the other. It is not irrelevant to an interpretation of the poem that Blake crossed it out; it is just that the poem is also a thing in the world, larger and more lasting than Blake's judgment of its merits. Others have come along and judged it quite good, and for them, too, the poem is both noumenon and phenomenon, a fact that makes their "judgment" in Smith's sense just as relevant and just as revisable as Blake's. Practical criticism takes place in the space in which judgments are deferred: "the point I am trying to make is that this final 'judgment' is a thing which must be indefinitely postponed" (xv). After the example from Blake, Empson brings up an exhibition of Constable then showing in which a 'study' that Constable clearly considered inferior to his finished canvas is in fact the more prized work at that moment. "Would Mr. James Smith say that the 'study', which is now more admired than the finished work, was a noumenon or a phenomenon? I do not see any way out of the dilemma which would leave the profound truths he was expressing much importance for a practical decision" (xv). Profound truths without much importance for the practicalities of interpretation: it is from this perspective that it seems not just desirable, but necessary, to leave a question unbroached and unanswered, "indefinitely."

I conclude with another snippet from Empson, this one from Some Versions of Pastoral, first published in 1935. Adam Phillips had seen Winnicott's approach to analytic interpretation as answering the "need of the self to be both intelligible and hidden" (Phillips 1988, 14). And when he came to describe how that stance toward the self showed up in Winnicott's style, he reached for the "pastoral": "the genre of simplicity in which Winnicott writes, a wry version of pastoral, is in fact a kind of elusiveness. But the shrewd ingenuousness of his writing [...] is consistent with one of his therapeutic aims: to protect the privacy of the self in the making of personal sense and, by the same token, personal non-sense" (14). Interpretation here is the vehicle of an ethics, one seeking understanding but respecting firm limits to it. But what does this have to do with "pastoral"? Empson suggests an answer:

The feeling that life is essentially inadequate to the human spirit, and yet that a good life must avoid saying so, is naturally at home with most versions of pastoral; in pastoral you take a limited life and pretend it is the full and normal one, and a suggestion that one must do this with all life, because the normal is itself limited, is easily put into the trick though not necessary to its power. Conversely any expression of the idea that all life is limited may be regarded as only a trick of pastoral, perhaps chiefly intended to hold all our attention and sympathy for some limited life, though again this is not necessary to it either on grounds of truth or beauty; in fact the suggestion of pastoral may be only a protection for the idea which must at last be taken alone. The business of interpretation is obviously very complicated. Literary uses of the problem of 
free-will and necessity, for example, may be noticed to give curiously bad arguments and I should think get their strength from keeping you in doubt between the two methods. Thus Hardy is fond of showing us an unusually stupid person subjected to very unusually bad luck, and then a moral is drawn, not merely by inference but by solemn assertion, that we are all in the same boat as this person whose story is striking precisely because it is unusual. The effect may be very grand, but to make an otherwise logical reader accept the process must depend on giving him obscure reasons for wishing it so. It is clear at any rate that this grand notion of the inadequacy of life, so various in its means of expression, needs to be counted as a possible territory of the pastoral. (Empson 1974, 114-115)

Reading this extraordinary passage, one cannot help agreeing that "the business of interpretation is obviously very complicated." There are, I think, two intersecting problems or levels: the question of "the inadequacy of life" and the question of how pastoral works. Taking the example of Hardy is perhaps the easiest way in: Hardy's grim texts are pastoral, thinks Empson, because the story of "an unusually stupid person subjected to very unusually bad luck" is somehow made to suggest that "we are all in the same boat as this person whose story is striking precisely because it is unusual." We can see how it works - Empson likes to call it the "trick" of pastoral but we cannot really say why it works: there must be "obscure reasons" in the reader "for wishing it so." And Empson's hunch is that those reasons are obscure, are made to remain obscure, because they touch on the "feeling that life is inadequate to the human spirit," that our own puny, mortal life is hopelessly "limited" with respect to all that our spirit may encompass. We are all living a "limited life" pretending to be "the full and normal one." Pastoral, it turns out, is a tried-and-true method for simultaneously expressing and hiding a self that is both limited and unlimited. Life is "essentially inadequate to the human spirit" but "a good life must avoid saying so" [emphasis mine]. It is this circumspection, this essential reserve, that pastoral addresses by offering "reasons" that remain "obscure." Interpretation here proceeds through a syncopation of expression and opacity. The individual both knows and does not say that life is inadequate to his spirit. The pastoral writer both knows, and does not say, that his audience has "obscure reasons for wishing it so." The literary critic both understands and remains puzzled by the "trick" of pastoral. All this succeeds only if certain questions are not forced. A good life must avoid saying certain things. The business of interpretation is obviously very complicated.

\section{Bibliography}

Cavell, Stanley. The Claim of Reason: Wittgenstein, Skepticism, Morality, and Tragedy. New York:

Oxford University Press, 1979.

Chaouli, Michel. "Criticism and Style." New Literary History 44 (2013): 323-344.

Empson, William. Seven Types of Ambiguity. New York: New Directors, 1947 [1930].

Empson, William. Some Versions of Pastoral. New York: New Directions, 1974 [1935].

Flaubert, Gustave. The Letters of Gustave Flaubert, 1830-1857. Ed. and trans. Francis Steegmuller.

Cambridge, MA: Harvard UP, 1979. 
Freud, Sigmund. Beyond the Pleasure Principle. Trans. James Strachey. New York: Norton, 1961 [1920].

Groensteen, Thierry. Comics and Narration. Trans. Ann Miller. Jackson: University Press of Mississippi, 2013 [2011].

Johnson, Barbara. Persons and Things. Cambridge, MA: Harvard UP, 2008.

Klein, Melanie. The Psycho-Analysis of Children. Trans. Alix Strachey. London: Hogarth Press, 1949 [1932].

Klein, Melanie. Narrative of a Child Analysis: The Conduct of the Psycho-Analysis of Children as seen in the Treatment of a Ten-year-old Boy. New York: The Free Press, 1961.

Phillips, Adam. Winnicott. Cambridge, MA: Harvard University Press, 1988.

Sontag, Susan. Against Interpretation. New York: Anchor Books, 1990 [1966].

Winnicott, D.W. Playing and Reality. London: Routledge, 1991 [1971]. 
